\title{
Impaired insulin signaling and spatial learning in middle-aged rats: The role of PTP1B
}

\author{
Gabriel Keine Kuga ${ }^{\mathrm{a}}$, Vitor Rosetto Muñoz ${ }^{\mathrm{b}}$, Rafael Calais Gaspar ${ }^{\mathrm{b}}$, \\ Susana Castelo Branco Ramos Nakandakari ${ }^{\mathrm{c}}$, Adelino Sanchez Ramos da Silva ${ }^{\mathrm{d}}$,
} José Diego Botezelli ${ }^{\mathrm{b}}$, José Alexandre Curiacos de Almeida Leme ${ }^{\mathrm{e}}$, Ricardo José Gomes ${ }^{\mathrm{f}}$, Leandro Pereira de Moura ${ }^{\mathrm{a}, \mathrm{b}, \mathrm{g}, \mathrm{h}}$, Dennys Esper Cintra ${ }^{\mathrm{c}, \mathrm{g}}$, Eduardo Rochete Ropelle ${ }^{\mathrm{b}, \mathrm{g}, \mathrm{h}}$, José Rodrigo Pauli ${ }^{\mathrm{b}, \mathrm{g}, \mathrm{h}, *}$

a Post-graduate Program in Movement Sciences, São Paulo State University (UNESP), Rio Claro, SP, Brazil

${ }^{\mathbf{b}}$ Laboratory of Molecular Biology of Exercise (LaBMEx), School of Applied Sciences, University of Campinas (UNICAMP), Limeira, SP, Brazil

${ }^{\mathrm{c}}$ Laboratory of Nutritional Genomics (LabGeN), School of Applied Sciences, University of Campinas (UNICAMP), Limeira, SP, Brazil

${ }^{\mathrm{d}}$ School of Physical Education and Sport of Ribeirao Preto, University of Sao Paulo, Ribeirao Preto, SP, Brazil

e Department of Physical Education, Catholic University Center Unisalesiano, Lins, SP, Brazil

${ }^{\mathrm{f}}$ Department of Biosciences, São Paulo Federal University (UNIFESP), Santos, SP, Brazil

${ }^{\mathrm{g}}$ Laboratory of Cell Signaling, Obesity and Comorbidities Research Center (OCRC), University of Campinas, Campinas, SP, Brazil

${ }^{\mathrm{h}}$ CEPECE - Center of Research in Sport Sciences, School of Applied Sciences, University of Campinas (UNICAMP), Limeira, SP, Brazil

\section{A R T I C L E I N F O}

Section Editor: Christian Humpel

Keywords:

PTP1B

Hippocampus

Insulin

Aging

BDNF

\begin{abstract}
A B S T R A C T
The insulin and Brain-Derived Neurotrophic Factor (BDNF) signaling in the hippocampus promotes synaptic plasticity and memory formation. On the other hand, aging is related to the cognitive decline and is the main risk factor for Alzheimer's Disease (AD). The Protein-Tyrosine Phosphatase 1B (PTP1B) is related to several deleterious processes in neurons and emerges as a promising target for new therapies. In this context, our study aims to investigate the age-related changes in PTP1B content, insulin signaling, $\beta$-amyloid content, and Tau phosphorylation in the hippocampus of middle-aged rats. Young ( 3 months) and middle-aged (17 months) Wistar rats were submitted to Morris-water maze (MWM) test, insulin tolerance test, and molecular analysis in the hippocampus. Aging resulted in increased body weight, and insulin resistance and decreases learning process in MWM. Interestingly, the middle-aged rats have higher levels of PTP-1B, lower phosphorylation of IRS-1, Akt, GSK3 $\beta$, mTOR, and TrkB. Also, the aging process increased Tau phosphorylation and $\beta$-amyloid content in the hippocampus region. In summary, this study provides new evidence that aging-related PTP1B increasing, contributing to insulin resistance and the onset of the AD.
\end{abstract}

\section{Introduction}

Aging is the main risk factor for the development of Alzheimer's Disease (AD), and the hippocampus is severely affected in this condition (Fjell et al., 2014; Kawas et al., 2000). Recent studies have shown that some pathogenic process behind aging-induced $\mathrm{AD}$ involves hippocampal insulin resistance (de la Monte and Wands, 2008; Lourenco et al., 2013; Vieira et al., 2017). The aging changes are linked to the inflammaging mechanism, which consists of increased levels of inflammatory proteins such as interleukin-1beta (IL1 $\beta$ ) and tumor necrosis factor alpha (TNF $\alpha$ ) (Franceschi et al., 2000; Giunta et al., 2008). Therefore, the inflammation connects the disruption of hippocampal insulin signaling to the pathogenic molecular mechanism of the $\mathrm{AD}$, leading some researchers to refer to the $\mathrm{AD}$ as type 3 diabetes (de la Monte and Wands, 2008).

Insulin plays a neurogenic, synaptogenic, and memory enhancer role in the hippocampus (Takeda et al., 2011; Vieira et al., 2017). At the molecular level, the appropriate hippocampal insulin signaling turns off several proteins involved in the AD molecular mechanism (Takeda et al., 2011; Vieira et al., 2017). A protein that is downstream to insulin signaling is Glycogen Synthase Kinase 3 beta (GSK3ß), which is phosphorylated and inactivated through the Phosphatidylinositol-4,5-bisphosphate 3-kinase (Pi3k)/Protein Kinase B (Akt) pathway (Takeda et al., 2011). When activated, the GSK3 $\beta$ is responsible for the Tau

\footnotetext{
* Corresponding author at: School of Applied Sciences, University of Campinas (UNICAMP), R. Pedro Zaccaria, 1300 Caixa Postal 1068, Jd. Sta. Luzia, CEP 13484-350 Limeira, Sao Paulo, Brazil.

E-mail address: jose.pauli@fca.unicamp.br (J.R. Pauli).
} 
phosphorylation. A hallmark of the $\mathrm{AD}$ is the Tau hyperphosphorylation (Takeda et al., 2011). Also, the increased circulating insulin competes with $\beta$-amyloid for degradation by Insulin Degrading Enzyme (Qiu et al., 1998; Qiu and Folstein, 2006; Takeda et al., 2011). Another feature of the $\mathrm{AD}$ is the accumulation of $\beta$-amyloid oligomers that disrupts the hippocampal insulin signaling and exerts a synaptotoxic effect (Lourenco et al., 2013).

The knowledge of the key factors responsible for the hippocampal insulin resistance is the interest to the scientific community. Several studies demonstrated that inflammation may increase the content of Protein Tyrosine Phosphatase-1B (PTP1B) in important targets of insulin such as skeletal muscle (Ropelle et al., 2006), liver (de Moura et al., 2013), and hypothalamus (Chiarreotto-Ropelle et al., 2013). Therefore, PTP1B is one of the major tyrosine phosphatases of the Insulin Receptor (IR), the IR Substrate-1 (IRS1), and the Tyrosine Kinase Receptor B (TrkB) (Chiarreotto-Ropelle et al., 2013; de Moura et al., 2013; Ozek et al., 2014; Ropelle et al., 2006; Vieira et al., 2017). Mice lacking PTP1B in the hippocampus present increased learning process evaluated by Barnes Maze test (Fuentes et al., 2012), suggesting the role of this protein as a negative regulator of memory (Vieira et al., 2017). These findings place the PTP1B as a key protein in the $\mathrm{AD}$ (Vieira et al., 2017).

However, the content of hippocampal PTP1B in middle-aged rats has not yet been demonstrated. The PTP1B may play an important role in the hippocampus during aging as a negative regulator of synapse formation and memory acquisition/formation, creating favorable conditions for the development of $\mathrm{AD}$. Therefore, this study aims to investigate the insulin/Brain-Derived Neurotrophic Factor (BDNF) signaling, the PTP1B content and the association of these molecular mechanisms with spatial learning in middle-aged rats.

\section{Materials and methods}

\subsection{Experimental animals}

Male young ( 3 months) and middle-aged (17 months) Wistar rats were used for the experimental procedures. The rats were obtained from the Multidisciplinary Center for Biological Investigation on Laboratory Animal Science (CEMIB) - University of Campinas (UNICAMP), kept in collective cages $\left(25^{\circ} \mathrm{C} \pm 1{ }^{\circ} \mathrm{C}\right.$ ) and fed with standard chow diet (Nuvilab ${ }^{\circledast}$ ) and water ad libitum. All procedures were approved by Animal Ethics Committee (CEUA) of the Institute of Biological Sciences, UNICAMP - Campinas-SP (case number 4257-1). The number of animals used in each experiment is specified in the figure legends.

\subsection{Insulin tolerance test (ITT)}

The ITT was performed after an $8 \mathrm{~h}$ fasting period, when the rats received an intraperitoneal injection of insulin (Humalog ${ }^{\oplus} ; 1.5 \mathrm{U} / \mathrm{kg}$ body weight) followed by blood sampling at $0,10,15,20,25$ and $30 \mathrm{~min}$. While blood glucose removal rate (kITT) was calculated using the formula $0.693 / \mathrm{t}_{1 / 2}$, the blood glucose half-time $\left(\mathrm{t}_{1 / 2}\right)$ was calculated from the least-squares regression slope of the blood glucose level along the linear phase of decline (Bonora et al., 1989).

\subsection{Morris water maze test (MWM)}

The MWM protocol was adapted from previous studies (Diegues et al., 2014; Li et al., 2014). The experiment was conducted in a circular pool (diameter: $2 \mathrm{~m}$; water depth: $70 \mathrm{~cm}$; water temperature $25 \pm 1{ }^{\circ} \mathrm{C}$ ) and a circular escape platform (diameter: $15 \mathrm{~cm}$ ). Firstly, the animals were adapted to the water environment during five days. During the four days of the test, the animals performed four attempts (maximum of the 60s each) starting in all quadrants (i.e., south, west, north and east). The water was clear on the first day of the test and darkened by the dye in the next days. The escape platform was placed in the center of the north quadrant and kept $5 \mathrm{~cm}$ above the water level on the first day and $5 \mathrm{~cm}$ below on the next days. The time that the rats spent to find the platform was recorded (latency escape time). If the rats did not find the platform, it was gently placed on the platform and stayed there for $15 \mathrm{~s}$. For the Probe Test that was performed $24 \mathrm{~h}$ after the fourth experimental day of MWM, the escape platform was removed from the pool and the animal performed a single trial of 2 min. During the Probe Test, the time the animal remained in the north quadrant (where the escape platform was previously located) was recorded.

\subsection{Tissue collection and Western Blotting analyses}

After the $8 \mathrm{~h}$ fasting period, the rats were anesthetized with intraperitoneal injection of ketamine chlorhydrate $(80 \mathrm{mg} / \mathrm{kg})$ and xylazine $(12 \mathrm{mg} / \mathrm{kg})$. After the corneal reflexes loss, the rats were stimulated with insulin $\left(10^{-6} \mathrm{~mol} / \mathrm{L}\right)$ through the hepatic portal vein. Five minutes later, the euthanasia was performed by decapitation, and the hippocampus was extracted. The tissue homogenization, the Western Blotting (SDS-PAGE polyacrylamide gel electrophoresis) protocol, and the visualization of bands [enhanced chemiluminescence and densitometry (UN-SCAN-IT gel 6.1)] were performed as recently described by our research group (Botezelli et al., 2016; Muñoz et al., 2017). Nitrocellulose membranes were incubated overnight at $4{ }^{\circ} \mathrm{C}$ with the following specific antibodies: Santa Cruz Biotechnology $=$ PTP1B (rabbit, sc-14021), pAKT ${ }^{\text {s473 }}$ (rabbit, sc-33437), Akt (rabbit, sc-8312), GSK3 $\beta$ (rabbit, sc-9166), BDNF (rabbit, sc-546), pTrkB ${ }^{\mathrm{y} 706}$ (rabbit, sc-135645), TrkB (rabbit, sc-8316), $\beta$-amyloid (mouse, sc-374527), pTAU ${ }^{\mathrm{s} 726}$ (goat, sc-16945); Cell Signaling Technology $=$ GAPDH (rabbit, \#2118), pGSK3 $^{\text {s9 }}$ (rabbit, \#5558s), pmTOR ${ }^{\text {s2448 }}$ (rabbit, \#5536), mTOR (rabbit, \#2983); Life Technologies $=$ pIRS1 $^{\text {Y612 }}$ (rabbit, \#44816G).

\subsection{Statistical analysis}

For the body weight, kITT and Western Blot data, a $t$-test was used. For the ITT data (main factors: group and time) and MWM data (main factors: group and day, we considered the mean of the 4 attempts of each animal per day), Anova two-way with Bonferroni post-hoc test was used. The significance level was established in 0.05 . The software GraphPad Prism 5.0 ${ }^{\circledR}$ was utilized for the analysis.

\section{Results}

\subsection{Middle-aged rats had lower insulin sensitivity and impaired spatial learning}

There was a significant increase in body weight $(t=7.459, d f=10$, $p<0.0001$ ) of middle-aged Wistar rats (Fig. 1A). As demonstrated by the insulin tolerance test (ITT), this phenomenon was associated with reduced insulin sensitivity when compared to young rats (Fig. 1B). The Anova two-way revealed a main effect of group $(F(1,8)=11.10$, $p=0.0104)$ and time $(F(5,40)=268.4, p<0.0001)$. Also, the kITT ( $t=2.917, d f=8, p=0.0194$ ) was lower in the middle-aged than young rats (Fig. 1C). All these parameters suggest an impairment of the insulin action in the middle-aged rats. Also, we investigated the cognition (spatial learning task) of these rats on MWM test. As expected, we found that both middle-aging and impaired insulin action were associated with learning deficit $(F(1,11)=5.159, p=0.442)$ (Fig. 1D). Besides the main group effect, we also found the main effect of time ( $F$ $(3,33)=4.184, p=0.129)$, indicating that the stimulus was enough for the rats to learn the task over the testing days. Moreover, the middle-aged animals presented deficits in memory retention $(t=2.697$, $d f=8, p=0.0272$ ) evaluated by the Probe Test (Fig. 1E). 


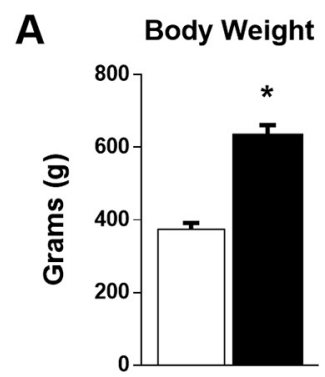

B

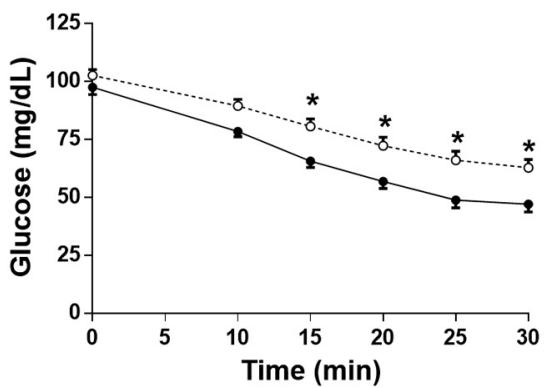

C

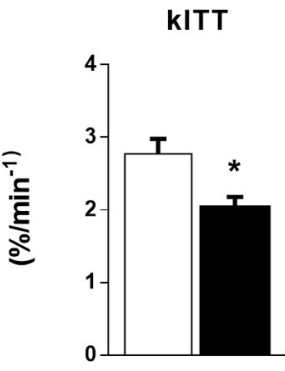

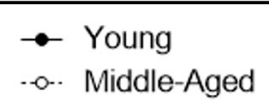

Middle-Aged
Young Middle-Aged
D

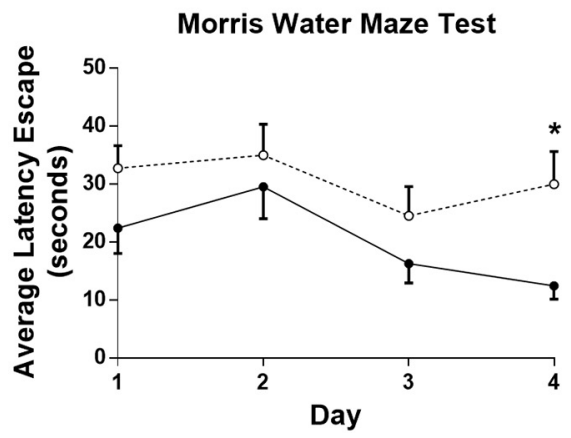

E

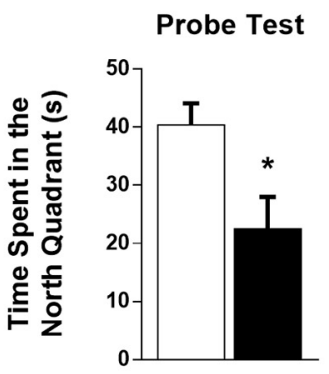

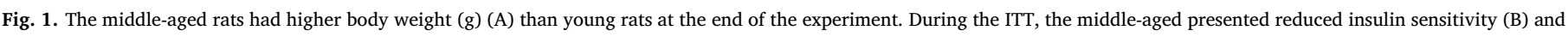

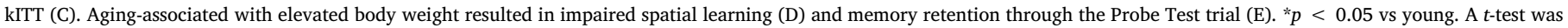
performed for the body weight, kITT, and Probe Test analyses. Anova two-way with Bonferroni post-hoc test was performed for ITT and MWM. ( $\mathrm{n}=5-7$ animals per group).

\subsection{Increased PTP1B content, reduced insulin/BDNF signaling and changes} related to $A D$ in the hippocampus of middle-aged rats

Interestingly, the molecular analyses showed an increased hippocampal PTP1B ( $t=3.013, d f=7, p=0.0196)$ content (Fig. 2A), a wellknown marker responsible for the disruption of insulin/BDNF signaling pathway through dephosphorylation of IR, IRS1, and TrkB.

In accordance, middle-aging was associated with significant reduction in the phosphorylation of IRS1 ( $t=2.595, d f=7, p=0.0357)$, Akt $(t=2.396, d f=7, \quad p=0.0479)$ and GSK3ß $(t=2.968, d f=7$, $p=0.0209$ ) (Fig. 3A-D). Although there was no significant difference in the content of hippocampal BDNF ( $t=1.576, d f=7, p=0.159)$, the middle-aged rats was showed reduced phosphorylation of TrkB $(t=2.571, d f=7, p=0.037)$ and mammalian target of rapamycin (mTOR) $(t=4.042, d f=7, p=0.0049)$ (Fig. $3 \mathrm{~A}, \mathrm{E}-\mathrm{G})$.

Increased hippocampal $\beta$-amyloid $(t=4.536, d f=7, p=0.0027)$ content combined with higher phosphorylation of Tau $(t=6.046$, $d f=7, p=0.0005$ ) (Fig. 4) were verified, suggesting that the molecular changes related to $\mathrm{AD}$ occur parallel to aging.

\section{Discussion}

The hippocampal insulin signaling promotes synaptic plasticity, neurogenesis, and memory formation (De Felice et al., 2014; Grillo et al., 2015). We found that middle-aged Wistar rats presented higher body weight and decreased insulin sensitivity. These changes are associated to impaired spatial learning compared to young rats. It is already known that the downregulation of IR specifically in the hippocampus resulted in deficits in the synaptic transmission associated with impairments in the spatial learning (Grillo et al., 2015). Several studies investigating insulin resistance/insufficiency described similar spatial learning deficits in diabetic (Diegues et al., 2014), obese (Liang et al., 2015) and aged (Gallagher et al., 2015) animals. An interesting study reviewed several transgenic $\mathrm{AD}$ models with a focus on performance in MWM and other behavioral assays (Puzzo et al., 2014). It is common for studies with transgenic models for the APP, presenilin and Tau to use
A

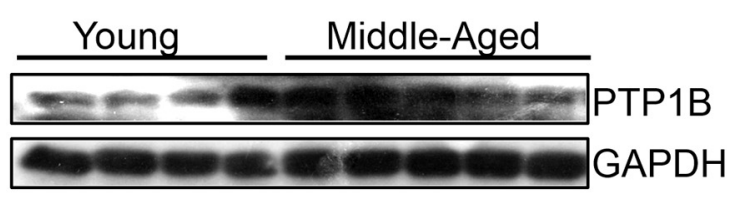

B

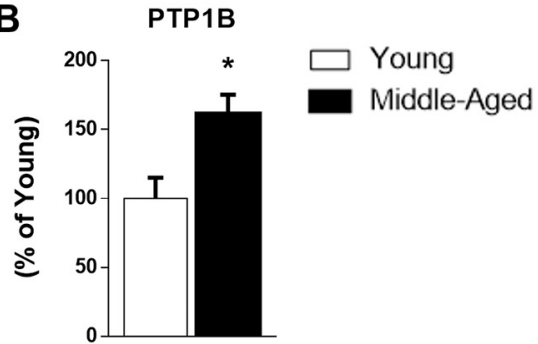

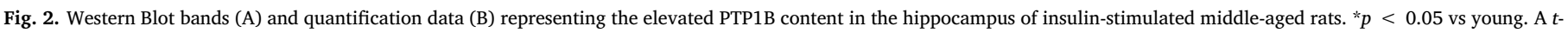
test was performed for this analysis. ( $n=4-5$ animals per group). 
A

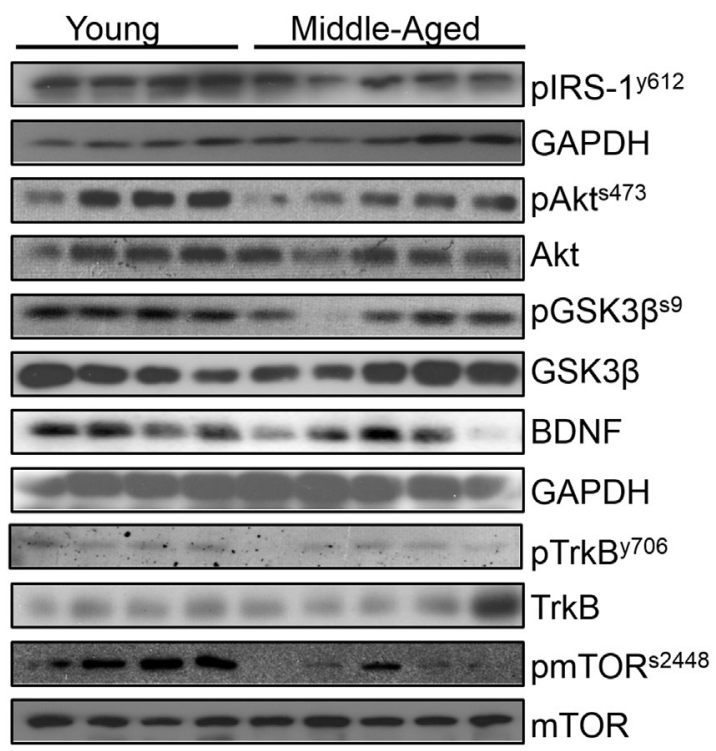

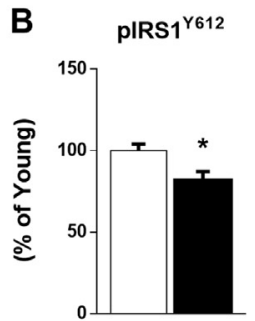
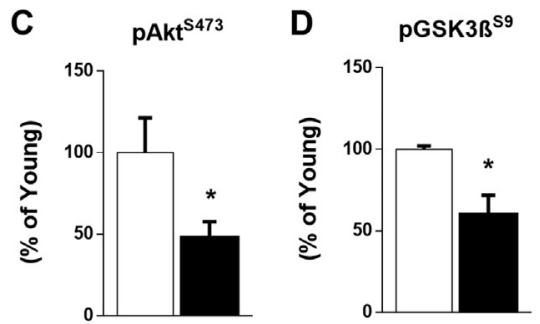

$\square$ Young

Middle-Aged
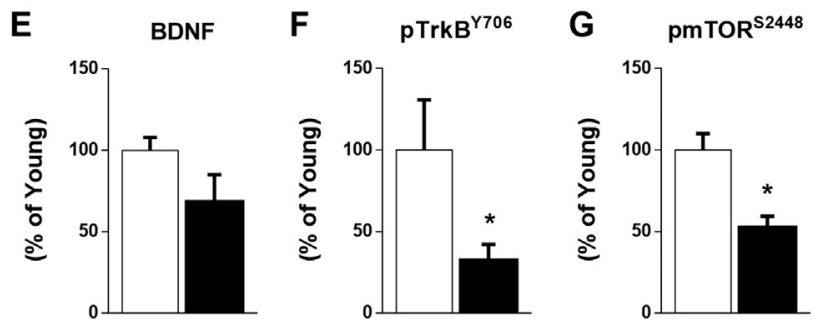

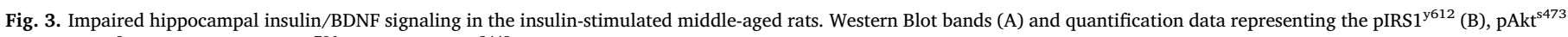

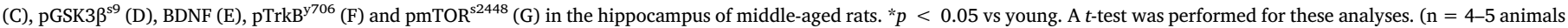
per group).

MWM to investigate cognitive dysfunctions and possible treatments for AD (Puzzo et al., 2014). Previously, reduced insulin signaling and increased inflammation mediators in postmortem human AD brains were verified (Bomfim et al., 2012; Vieira et al., 2017), connecting the defective insulin action to development of $\mathrm{AD}$. Considering that aging is strongly associated with $\mathrm{AD}$ development, we showed that this natural process is accompanied by increased hippocampus PTP1B content, indicating the role of this phosphatase in the disruption of insulin signaling pathway in the later stages of life.

Previous studies demonstrated that aging increases the PTP1B content in several target tissues of insulin action such as liver (de Moura et al., 2013), skeletal muscle (González-Rodríguez et al., 2012), and hypothalamus (Morrison et al., 2007). However, this is the first study showing the increased PTP1B content in the hippocampus of middleaged rats. PTP1B is the main phosphatase of tyrosine residues of IR, IRS1, and TrkB (de Moura et al., 2013; Ozek et al., 2014; Ropelle et al., 2006; Vieira et al., 2017), disrupting the insulin/BDNF signaling pathway and contributing to the decline of cognitive functions in middle-aged rats.

Next, we evaluated the key proteins of the insulin signaling cascade. Middle-aged animals showed remarkable reductions in the Akt and GSK3 $\beta$ phosphorylation. This process can be explained partially due to the increased $\beta$-amyloid content. The $\beta$-amyloid is a synaptic toxin that activates the TNF- $\alpha /$ PKR/eIF2 $\alpha$ pathway, inducing the endoplasmic reticulum stress and resulting in the inhibition, internalization, and degradation of IR (Lourenco et al., 2013). Another downstream effect of the reduced hippocampal insulin signaling is the activation of GSK3 $\beta$ and enhanced phosphorylation of Tau protein, a hallmark of the AD molecular mechanism and a trigger to neuronal apoptosis (Schubert et al., 2004). Our findings indicate that the decreased GSK3 $\beta$ phosphorylation occurs parallel to increased Tau phosphorylation in the hippocampus of middle-aged rats. The insulin signaling seems to exert an important protective effect against $\mathrm{AD}$ in the hippocampus. The intracerebral injection of streptozotocin, a pro-diabetic drug, resulted in deficits in the hippocampal insulin signaling pathway, increased both Tau phosphorylation and gene expression of the amyloid precursor protein (Lester-Coll et al., 2006). This process is also accompanied by impaired spatial learning (de la Monte et al., 2006). It is also currently proposed that these molecular mechanisms are also linked to aging (Herrup, 2010; Palmeri et al., 2013), suggesting that the pathogenesis of Alzheimer's Disease in aging is associated with hippocampal insulin resistance.

In addition, the middle-aged rats presented a non-significant $(p=0.159)$ decrease in hippocampal BDNF concentration. BDNF is a growth factor that exerts important effect (like insulin) stimulating synaptic plasticity, memory formation, and neurogenesis (Vieira et al., 2017). This process begins with the binding of BDNF to its receptor (TrkB), triggering the Pi3k/Akt pathway (Ozek et al., 2014). Another relevant protein stimulated by the BDNF signaling is the mTOR, which is important to the synthesis of synaptic proteins and memory consolidation (Bekinschtein et al., 2007; Slipczuk et al., 2009). Although there was limited evidence about age-related effects on mTOR
A

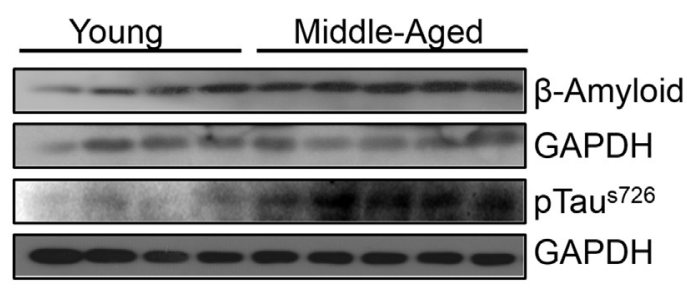

B$$
\text { B }
$$

C

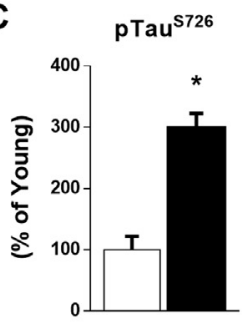

Young

Middle-Aged

Fig. 4. Alterations in the content of the proteins involved in the AD pathogenesis. Western Blot bands (A) and quantification data representing the $\beta$-amyloid (B) and $\mathrm{pTau}{ }^{\mathrm{s} 726}$ (C) in the hippocampus of insulin-stimulated middle-aged rats. ${ }^{*} p<0.05$ vs young. A $t$-test was performed for these analyses. $(\mathrm{n}=4-5$ animals per group). 
phosphorylation, an interesting study showed that the activity of mTOR and its upstream signaling in hippocampus declined with aging (Yang et al., 2014). In our study, mTOR had lower phosphorylation (like TrkB) in the middle-aged rats, suggesting an additional molecular mechanism to explain the impaired spatial learning. A possible trigger for this process is the increased PTP1B content and the resulting dephosphorylation of TrkB.

Thus, PTP1B was associated with impaired spatial learning and insulin/BDNF signaling in the hippocampus through dephosphorylation of IR, IRS-1, and TrKB. Herein, we showed new evidence about the agerelated effect increasing the PTP1B content and reducing the insulin/ BDNF signaling in the hippocampus. Further research is relevant to assess whether inhibition of PTP1B in the hippocampus of middle-aged animals alters spatial learning and memory retention. Moreover, it is important to note that the deletion of PTP1B in the hippocampus resulted in better performance of young animals in the Barnes Maze test (Fuentes et al., 2012). However, it has not been described whether the inhibition or deletion of this protein in the hippocampus of aged animals is able to prevent or attenuate the deficits and the pathogenesis of AD.

In summary, the current data provided new insights into the hippocampal molecular mechanism related to cognitive decline and $\mathrm{AD}$ pathogenesis. Also, interventions to modulate PTP1B activity in the hippocampus may be an attractive strategy to decelerate or prevent AD development in aged individuals.

\section{Acknowledgements}

The authors thank MR Sant'Ana, L Breda, and RM Pereira for all support during the experiment.

\section{Author contributions}

G.K.K. was responsible for the MWM test, the molecular analyses and wrote the paper. V.R.M. and R.C.G. were responsible for the physiological tests and the molecular analyses. S.C.B.R.N. was responsible for the MWM test and wrote the paper. J.D.B., J.A.C.A.L., R.J.G. and A.S.R.S. reviewed the paper. L.P.M., D.E.C. and E.R.R. reviewed the paper and provided laboratory support. J.R.P. was responsible for the experimental design, the research funding, the laboratory support and final review.

\section{References}

Bekinschtein, P., Katche, C., Slipczuk, L.N., Igaz, L.M., Cammarota, M., Izquierdo, I., Medina, J.H., 2007. mTOR signaling in the hippocampus is necessary for memory formation. Neurobiol. Learn. Mem. 87, 303-307. http://dx.doi.org/10.1016/j.nlm. 2006.08.007.

Bomfim, T.R., Forny-Germano, L., Sathler, L.B., Brito-Moreira, J., Houzel, J.-C., Decker, H., Silverman, M.A., Kazi, H., Melo, H.M., McClean, P.L., Holscher, C., Arnold, S.E., Talbot, K., Klein, W.L., Munoz, D.P., Ferreira, S.T., De Felice, F.G., 2012. An antidiabetes agent protects the mouse brain from defective insulin signaling caused by Alzheimer's disease-associated A $\beta$ oligomers. J. Clin. Invest. 122, 1339-1353. http:// dx.doi.org/10.1172/JCI57256.

Bonora, E., Moghetti, P., Zancanaro, C., Cigolini, M., Querena, M., Cacciatori, V., Corgnati, A., Muggeo, M., 1989. Estimates of in vivo insulin action in man: comparison of insulin tolerance tests with euglycemic and hyperglycemic glucose clamp studies*. J. Clin. Endocrinol. Metab. 68, 374-378. http://dx.doi.org/10.1210/jcem 68-2-374.

Botezelli, J.D., Coope, A., Ghezzi, A.C., Cambri, L.T., Moura, L.P., Scariot, P.P.M., Gaspar, R.S., Mekary, R.A., Ropelle, E.R., Pauli, J.R., 2016. Strength training prevents hyperinsulinemia, insulin resistance, and inflammation independent of weight loss in fructose-fed animals. Sci. Rep. 6, 31106. http://dx.doi.org/10.1038/srep31106.

Chiarreotto-Ropelle, E.C., Pauli, L.S.S., Katashima, C.K., Pimentel, G.D., Picardi, P.K, Silva, V.R.R., de Souza, C.T., Prada, P.O., Cintra, D.E., Carvalheira, J.B.C., Ropelle, E.R., Pauli, J.R., 2013. Acute exercise suppresses hypothalamic PTP1B protein level and improves insulin and leptin signaling in obese rats. Am. J. Physiol. Endocrinol. Metab. 305, E649-59. http://dx.doi.org/10.1152/ajpendo.00272.2013.

De Felice, F.G., Lourenco, M.V., Ferreira, S.T., 2014. How does brain insulin resistance develop in Alzheimer's disease? Alzheimers Dement. 10, S26-S32. http://dx.doi.org/ 10.1016/j.jalz.2013.12.004.

de la Monte, S.M., Wands, J.R., 2008. Alzheimer's disease is type 3 diabetes-evidence reviewed. J. Diabetes Sci. Technol. 2, 1101-1113.

de la Monte, S.M., Tong, M., Lester-Coll, N., Plater, M., Wands, J.R., 2006. Therapeutic rescue of neurodegeneration in experimental type 3 diabetes: relevance to Alzheimer's disease. J. Alzheimers Dis. 10, 89-109.

de Moura, L.P., Souza Pauli, L.S., Cintra, D.E., de Souza, C.T., da Silva, A.S.R., Marinho, R., de Melo, M.A.R., Ropelle, E.R., Pauli, J.R., 2013. Acute exercise decreases PTP-1B protein level and improves insulin signaling in the liver of old rats. Immun. Ageing 10, 8. http://dx.doi.org/10.1186/1742-4933-10-8.

Diegues, J.C., Pauli, J.R., Luciano, E., de Almeida Leme, J.A.C., de Moura, L.P., Dalia, R.A., de Araújo, M.B., Sibuya, C.Y., de Mello, M.A.R., Gomes, R.J., 2014. Spatial memory in sedentary and trained diabetic rats: molecular mechanisms. Hippocampus 24, 703-711. http://dx.doi.org/10.1002/hipo.22261.

Fjell, A.M., McEvoy, L., Holland, D., Dale, A.M., Walhovd, K.B., Alzheimer's Disease Neuroimaging Initiative, 2014. What is normal in normal aging? Effects of aging, amyloid and Alzheimer's disease on the cerebral cortex and the hippocampus. Prog. Neurobiol. 117, 20-40. http://dx.doi.org/10.1016/j.pneurobio.2014.02.004.

Franceschi, C., Bonafè, M., Valensin, S., Olivieri, F., De Luca, M., Ottaviani, E., De Benedictis, G., 2000. Inflamm-aging. An evolutionary perspective on immunosenescence. Ann. N. Y. Acad. Sci. 908, 244-254.

Fuentes, F., Zimmer, D., Atienza, M., Schottenfeld, J., Penkala, I., Bale, T., Bence, K.K., Arregui, C.O., 2012. Protein tyrosine phosphatase PTP1B is involved in hippocampal synapse formation and learning. PLoS One 7, e41536. http://dx.doi.org/10.1371/ journal.pone.0041536.

Gallagher, M., Burwell, R., Burchinal, M., 2015. Severity of spatial learning impairment in aging: development of a learning index for performance in the Morris water maze. Behav. Neurosci. 129, 540-548. http://dx.doi.org/10.1037/bne0000080.

Giunta, B., Fernandez, F., Nikolic, W.V., Obregon, D., Rrapo, E., Town, T., Tan, J., 2008 Inflammaging as a prodrome to Alzheimer's disease. J. Neuroinflammation 5, 51. http://dx.doi.org/10.1186/1742-2094-5-51.

González-Rodríguez, Á., Más-Gutierrez, J.A., Mirasierra, M., Fernandez-Pérez, A., Lee, Y.J., Ko, H.J., Kim, J.K., Romanos, E., Carrascosa, J.M., Ros, M., Vallejo, M., Rondinone, C.M., Valverde, Á.M., 2012. Essential role of protein tyrosine phosphatase $1 \mathrm{~B}$ in obesity-induced inflammation and peripheral insulin resistance during aging. Aging Cell 11, 284-296. http://dx.doi.org/10.1111/j.1474-9726.2011. 00786.x.

Grillo, C.A., Piroli, G.G., Lawrence, R.C., Wrighten, S.A., Green, A.J., Wilson, S.P., Sakai, R.R., Kelly, S.J., Wilson, M.A., Mott, D.D., Reagan, L.P., 2015. Hippocampal insulin resistance impairs spatial learning and synaptic plasticity. Diabetes 64, 3927-3936. http://dx.doi.org/10.2337/db15-0596.

Herrup, K., 2010. Reimagining Alzheimer's disease-an age-based hypothesis. J. Neurosci. 30, 16755-16762. http://dx.doi.org/10.1523/JNEUROSCI.4521-10.2010.

Kawas, C., Gray, S., Brookmeyer, R., Fozard, J., Zonderman, A., 2000. Age-specific incidence rates of Alzheimer's disease: the Baltimore longitudinal study of aging. Neurology 54, 2072-2077.

Lester-Coll, N., Rivera, E.J., Soscia, S.J., Doiron, K., Wands, J.R., de la Monte, S.M., 2006. Intracerebral streptozotocin model of type 3 diabetes: relevance to sporadic Alzheimer's disease. J. Alzheimers Dis. 9, 13-33.

Li, R., Zang, A., Zhang, L., Zhang, H., Zhao, L., Qi, Z., Wang, H., 2014. Chrysin ameliorates diabetes-associated cognitive deficits in Wistar rats. Neurol. Sci. 35, 1527-1532. http://dx.doi.org/10.1007/s10072-014-1784-7.

Liang, L., Chen, J., Zhan, L., Lu, X., Sun, X., Sui, H., Zheng, L., Xiang, H., Zhang, F., 2015. Endoplasmic reticulum stress impairs insulin receptor signaling in the brains of obese rats. PLoS One 10, e0126384. http://dx.doi.org/10.1371/journal.pone.0126384.

Lourenco, M.V., Clarke, J.R., Frozza, R.L., Bomfim, T.R., Forny-Germano, L., Batista, A.F., Sathler, L.B., Brito-Moreira, J., Amaral, O.B., Silva, C.A., Freitas-Correa, L., EspíritoSanto, S., Campello-Costa, P., Houzel, J.-C., Klein, W.L., Holscher, C., Carvalheira, J.B., Silva, A.M., Velloso, L.A., Munoz, D.P., Ferreira, S.T., De Felice, F.G., 2013. TNF$\alpha$ mediates PKR-dependent memory impairment and brain IRS-1 inhibition induced by Alzheimer's $\beta$-amyloid oligomers in mice and monkeys. Cell Metab. 18, 831-843. http://dx.doi.org/10.1016/j.cmet.2013.11.002.

Morrison, C.D., White, C.L., Wang, Z., Lee, S.-Y., Lawrence, D.S., Cefalu, W.T., Zhang, Z.Y., Gettys, T.W., 2007. Increased hypothalamic protein tyrosine phosphatase 1B contributes to leptin resistance with age. Endocrinology 148, 433-440. http://dx.doi. org/10.1210/en.2006-0672.

Muñoz, V.R., Gaspar, R.C., Crisol, B.M., Formigari, G.P., Sant'Ana, M.R., Botezelli, J.D., Gaspar, R.S., da Silva, A.S.R., Cintra, D.E., de Moura, L.P., Ropelle, E.R., Pauli, J.R., 2017. Physical exercise reduces pyruvate carboxylase (PCB) and contributes to hyperglycemia reduction in obese mice. J. Physiol. Sci. http://dx.doi.org/10.1007/ s12576-017-0559-3.

Ozek, C., Kanoski, S.E., Zhang, Z.-Y., Grill, H.J., Bence, K.K., 2014. Protein-tyrosine phosphatase 1B (PTP1B) is a novel regulator of central brain-derived neurotrophic factor and tropomyosin receptor kinase B (TrkB) signaling. J. Biol. Chem. 289, 31682-31692. http://dx.doi.org/10.1074/jbc.M114.603621.

Palmeri, A., Privitera, L., Giunta, S., Loreto, C., Puzzo, D., 2013. Inhibition of phosphodiesterase-5 rescues age-related impairment of synaptic plasticity and memory. Behav. Brain Res. 240, 11-20. http://dx.doi.org/10.1016/j.bbr.2012.10.060.

Puzzo, D., Lee, L., Palmeri, A., Calabrese, G., Arancio, O., 2014. Behavioral assays with mouse models of Alzheimer's disease: practical considerations and guidelines. Biochem. Pharmacol. 88, 450-467. http://dx.doi.org/10.1016/j.bcp.2014.01.011.

Qiu, W.Q., Folstein, M.F., 2006. Insulin, insulin-degrading enzyme and amyloid- $\beta$ peptide in Alzheimer's disease: review and hypothesis. Neurobiol. Aging 27, 190-198. http:// dx.doi.org/10.1016/j.neurobiolaging.2005.01.004.

Qiu, W.Q., Walsh, D.M., Ye, Z., Vekrellis, K., Zhang, J., Podlisny, M.B., Rosner, M.R., Safavi, A., Hersh, L.B., Selkoe, D.J., 1998. Insulin-degrading enzyme regulates extracellular levels of amyloid beta-protein by degradation. J. Biol. Chem. 273, 32730-32738. 
Ropelle, E.R., Pauli, J.R., Prada, P.O., de Souza, C.T., Picardi, P.K., Faria, M.C., Cintra, D.E., Fernandes, M.F. de A., Flores, M.B., Velloso, L.A., Saad, M.J.A., Carvalheira, J.B.C., 2006. Reversal of diet-induced insulin resistance with a single bout of exercise in the rat: the role of PTP1B and IRS-1 serine phosphorylation. J. Physiol. 577, 997-1007. http://dx.doi.org/10.1113/jphysiol.2006.120006.

Schubert, M., Gautam, D., Surjo, D., Ueki, K., Baudler, S., Schubert, D., Kondo, T., Alber, J., Galldiks, N., Kustermann, E., Arndt, S., Jacobs, A.H., Krone, W., Kahn, C.R., Bruning, J.C., 2004. Role for neuronal insulin resistance in neurodegenerative diseases. Proc. Natl. Acad. Sci. 101, 3100-3105. http://dx.doi.org/10.1073/pnas. 0308724101.

Slipczuk, L., Bekinschtein, P., Katche, C., Cammarota, M., Izquierdo, I., Medina, J.H., 2009. BDNF activates mTOR to regulate GluR1 expression required for memory formation. PLoS One 4, e6007. http://dx.doi.org/10.1371/journal.pone.0006007. Takeda, S., Sato, N., Rakugi, H., Morishita, R., 2011. Molecular mechanisms linking diabetes mellitus and Alzheimer disease: beta-amyloid peptide, insulin signaling, and neuronal function. Mol. BioSyst. 7, 1822-1827. http://dx.doi.org/10.1039/ c0mb00302f.

Vieira, M.N.N., Lyra e Silva, N.M., Ferreira, S.T., De Felice, F.G., 2017. Protein tyrosine phosphatase 1B (PTP1B): a potential target for Alzheimer's therapy? Front. Aging Neurosci. 9, 7. http://dx.doi.org/10.3389/fnagi.2017.00007.

Yang, F., Chu, X., Yin, M., Liu, X., Yuan, H., Niu, Y., Fu, L., 2014. mTOR and autophagy in normal brain aging and caloric restriction ameliorating age-related cognition deficits. Behav. Brain Res. 264, 82-90. http://dx.doi.org/10.1016/j.bbr.2014.02.005. 